\title{
Efeito do treinamento físico e da ingestão crônica de cafeína sobre o tecido ósseo de ratos jovens
}

CDD. 20.ed. 613.7

616.86

796.073

\author{
Solange de Paula RAMOS* \\ Vanessa Batista da Costa SANTOS ${ }^{* *}$ \\ Roberto J osé RUIZ ${ }^{* * *}$ \\ Maria Carla Perozim PRETT**** \\ Mayara Caroline VENTURA ${ }^{* *}$ \\ Maiara Santos NOGUEIRA* \\ Francelaine Bruna CAMPANA** \\ Sérgio Swain MÜLLER ${ }^{* * * * *}$ \\ Marcos Doederlein POLITO*** \\ Claudia Patrícia Cardoso Martins SIQUEIRA*
}

*Departamento de Histologia, Universidade

Estadual de Londrina.

**Departamento de

Fisioterapia, Univer-

sidade Estadual de Londrina.

***Departamento de Educação Física, Universidade Estadual de Londrina.

${ }^{\star * \star *}$ Departamento de Medicina Veterinária Preventiva, Universidade Estadual de Londrina.

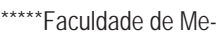
dicina, Universidade Estadual Paulista - Botucatu.

Foram avaliados os efeitos da ingestão crônica de cafeína e exercício de natação sobre o tecido ósseo. Ratos Wistar jovens $(n=32)$ alocados em quatro grupos: sedentário controle (SCO), sedentário + cafeína (SCAF), treinados (TCO) e treinados + cafeína (TCAF), receberam $1 \mathrm{mg} / \mathrm{ml}$ de cafeína em água durante 30 dias (SCAF e TCAF) e foram submetidos a 21 dias de natação em intensidade moderada (TCO e TCAF). A tíbia esquerda foi submetida a ensaio biomecânico para determinação do coeficiente de rigidez, limite de elasticidade e carga máxima. A área de tecido ósseo primário e espessura do disco epifisário foram avaliadas no fêmur. Não foram observadas alterações nas propriedades biomecânicas e na deposição de tecido ósseo primário. 0 grupo SCAF apresentou maior espessura no disco epifisário distal. Os resultados sugerem que o treinamento moderado de natação e a ingestão de cafeína não provocaram alterações morfológicas e biomecânicas do tecido ósseo.

Unitermos: Osso; Cafeína; Exercício.

\section{Introdução}

Apesar de a cafeína ser consumida em alimentos e bebidas, e ser utilizada frequentemente como recurso ergogênico em atividades esportivas (BURKE, 2008; Goldstein, Ziegenfuss, Kalman, Kreider, Campbell, Wilborn, Taylor, Willoughby, Stout, Graves, Wildman, Ivy, Spano, Smith \& Antonio, 2010), estudos "in vivo" e "in vitro" demonstram que a droga possui efeitos sobre o processo de remodelamento do tecido ósseo, sendo apontada como um possível fator de risco para a osteoporose (Duarte, Marques, Bezerra \& Bastos, 2009; Hallstrom, Wolk, Glynn \&Michalsson, 2006; LiU, Chen, Yang, Yen, Yang \& Tsai, 2011; Rapuri, Gallagher, Kinyamu \& Ryschon, 2001). Estudos em animais demonstraram que o consumo crônico de cafeína provoca redução da densidade mineral óssea (Lacerda, Matuoka, Macedo, Petenusci, Campos \& Brentegani, 2010; LiU et al., 2011), afetando o processo de neoformação e de remodelamento do tecido em animais jovens (DUARTE et al., 2009). Em estudos longitudinais em humanos, o consumo de bebidas cafeinadas provocou alterações no processo de remodelamento ósseo, sem alterar significativamente a densidade óssea em indivíduos jovens (Libuda, Alexy, Remer, Stehle, Schoenau \& KeRsting, 2008; WeTMORE, ICHIKAWA, LACrOIX, OTT $\&$ SCHOLES, 2008). Muitos dos estudos sobre cafeína e metabolismo ósseo foram realizados em mulheres idosas, e apresentando outros fatores de risco para a perda de densidade óssea como, por exemplo, o 
sedentarismo e depleção hormonal (HaLlSTROM et al., 2006; Hansen, Folsom, Kushi \& Sellers, 2000; Rapuri, Gallagher, Kinyamu \& Ryschon, 2001).

O exercício físico pode ter efeito antagonista à perda de cálcio induzida pela cafeína, protegendo o tecido ósseo (HuAng, Yang, Hsieh \& Liu, 2002). A estimulação mecânica sobre o tecido ósseo parece favorecer a atividade osteoblástica e a sobrevida de osteócitos, além de aumentar a densidade óssea mineral (GOULET, HALONEN, KoCh, Britton, Zernicke \& KoZloff, 2011; KeMmLer, Von Stengel, Bebenek, Engelke, Hentschke \& Kalender, 2011; Mann, Huber, Kogianni, Jones \& Noble, 2006). Os efeitos protetores do exercício físico podem ser mais eficazes em exercícios de força e impacto, sendo que a natação promove efeitos menos pronunciados no aumento da densidade óssea mineral em animais jovens (HInd, Gannon, Whatley, CoOKE

\section{Método}

Foram utilizados 32 ratos machos, Wistar, com aproximadamente 250 gramas, obtidos do Biotério do Centro da Universidade Estadual de Londrina. Os animais foram mantidos em gaiolas à temperatura controlada de $25^{\circ} \mathrm{C}$, sendo fornecida ração normocalórica $\mathrm{NUVILAB}^{\circledR}$ e água potável "ad libitum". Este estudo foi aprovado pelo Comitê de Ética para o Uso de Animais da Universidade Estadual de Londrina, parecer CEUA 028/10.

A amostra foi dividida em quatro grupos de oito animais, sendo eles: sedentário controle (SCO), sedentários com cafeína (SCAF), treinados controle (TCO) e treinados com cafeína (TCAF).

Os animais dos grupos SCAF e TCAF foram suplementados com $1 \mathrm{mg} / \mathrm{ml}$ de cafeína diluída em água potável, durante um período de 30 dias, por meio de ingestão voluntária (LORENZO, LEON, CAStillo, Ruiz, Albasanz \& Martín, 2010), enquanto os animais do grupo SCO e TCO receberam água
\& Truscott, 2011; Huang, Lin, Chang, Hsieh, Liu \& Yang, 2003; Mudd, Fornetti \& Pivarnik, 2007; Warner, Shea, Miller \& ShaW, 2006). Como o uso de altas doses de cafeína tem sido aplicado como recurso ergogênico associado ao treinamento físico, inclusive em indivíduos jovens e praticantes de natação (Dascombe, Karunaratna, Cartoon, Fergie \& GOODMAN, 2010), torna-se necessário conhecer os efeitos do consumo crônico de cafeína e sua interação com o tecido ósseo nos indivíduos treinados.

Considerando que a associação entre os efeitos da cafeína sobre o tecido ósseo ainda são controversos e necessitam de maiores investigaçôes, o objetivo do presente estudo foi analisar a estrutura histológica do fêmur e propriedades biomecânicas da tíbia de ratos Wistar submetidos a um período de treinamento físico com suplementação de cafeína.

potável. O volume de ingestão líquida e o consumo de ração foram avaliados no primeiro, décimo e vigésimo dia de treinamento.

Os grupos TCO e TCAF foram submetidos ao treinamento de natação, por um período de 21 dias, realizados cinco vezes por semana, em intensidade moderada (Carvalho, Masuda \& Pompeu, 2005; Ravi Kiran, Subramanyam \& Asha Devi, 2004) em tanques individuais, com temperatura da água entre $28^{\circ} \mathrm{C}$ a $32^{\circ} \mathrm{C}$. Os animais foram submetidos a um período de familiarização com o ambiente aquático, durante cinco dias, em tanques com $10 \mathrm{~cm}$ de água no primeiro dia, aumentando diariamente o volume de água, até completar $30 \mathrm{~cm}$ de profundidade. Os animais que não apresentaram comportamento de natação voluntária foram excluídos. O protocolo de treinamento foi iniciado com sete minutos de treino sem carga, e aumentado gradativamente conforme TABELA 1.

TABELA 1 - Protocolo de exercício.

\begin{tabular}{lcccccccc}
\hline Dias & Primeira semana & $\mathbf{1 - 2}$ & $\mathbf{3 - 5}$ & $\mathbf{6 - 8}$ & $\mathbf{9 - 1 2}$ & $\mathbf{1 3}-\mathbf{1 6}$ & $\mathbf{1 7}-\mathbf{2 0}$ & $\mathbf{2 1}$ \\
\hline Tempo (min) & $\begin{array}{c}\text { Familiarização ao } \\
\text { meio aquático }\end{array}$ & 7 & 10 & 15 & 20 & 25 & 30 & 40 \\
Carga(\%peso) & 0 & 0 & 0 & $3 \%$ & $3-4 \%$ & $4 \%$ & $4 \%$ & $4 \%$ \\
\hline
\end{tabular}

Os animais foram pesados, no inicio do treinamento, e semanalmente, até o fim do experimento para ajuste de cargas de treino. As cargas de treino variaram de $3 \%$ a $4 \%$ do peso corporal e foram fixados ao abdômen do animal durante o treinamento. 
Imediatamente após a última sessão de treino, os animais foram sedados em éter etílico e $1 \mathrm{ml}$ de sangue foi coletado em tubos de ensaio contendo fluoreto de sódio, por punção cardíaca. As amostras de sangue foram centrifugadas e submetidas a dosagem de lactato (Biotecnica, Varginha, Brasil). Após 24 horas da última sessão de treino, os animais foram novamente sedados para coleta de sangue, via punção cardíaca. As amostras foram centrifugadas e o soro foi separado para dosagem de cálcio e creatina quinase, utilizando kits comerciais (Biotecnica, Varginha, Brasil), conforme instruções do fabricante.

Os animais foram sacrificados por inalação de dose letal de éter etílico. A tíbia direita foi removida e utilizada como corpo de prova para análise biomecânica e o fêmur esquerdo foi utilizado para análise histológica.

Para determinação das propriedades mecânicas, foi realizado ensaio de flexão em três pontos utilizando a Máquina Universal de Ensaios Mecânicos (Emic Modelo DL10000). O corpo de prova (tíbia direita) foi posicionado com apoio nas extremidades e a carga perpendicular incidiu sobre a metáfise. A distância entre os dois apoios de suporte foi padronizada em dois terços do comprimento do corpo de prova. O cutelo de aplicação de carga foi posicionado em ponto equidistante às extremidades. As propriedades biomecânicas analisadas foram a carga máxima $(\mathrm{N})$ - carga máxima suportada pelo corpo de prova até a ruptura; o limite de elasticidade $(\mathrm{N})$ - ponto final da fase elástica linear; e o coeficiente de rigidez $(\mathrm{N} / 10-3 \mathrm{~m})$ - relação entre carga e deformação do diagrama até o limite de elasticidade (HuANG et al., 2003, 2010).

O fêmur foi fixado em solução de formalina tamponada $10 \%$, durante 24 horas, e descalcificado durante 21 dias em solução de ácido etilenodiaminotetracético 10\% (pH 7.2) em corrente elétrica de $75 \mathrm{mV}$. As amostras foram incluídas em parafina histológica e cortes de $7 \mu \mathrm{m}$ foram submetidos a coloração de hematoxilina e eosina.

As imagens histológicas foram capturadas em câmera MOTICAN (Motic Company, Xiamen, China) e analisadas em "software" Motic Image Plus 2.0 (Motic Company, Xiamen, China). Três imagens do disco epifisário proximal e distal, e três imagens do osso esponjoso da diáfise medial e distal de cada animal, foram capturadas em aumentos de 40x. Foram avaliadas a espessura média do disco epifisário e a área das trabéculas ósseas do osso esponjoso.

A distribuição de normalidade dos dados foi avaliada pelo teste de Kolmogorov-Smornov. A comparação entre grupos com distribuição paramétrica foi avaliada pelo teste ANOVA two-way, com teste "post hoc" de Tukey. Dados com distribuição não-paramétrica foram tratados com o teste Kruskal-Wallis e teste "post hoc" de Dunn. As diferenças entre os grupos foram consideradas significantes quando $\mathrm{P}<0,05$.

\section{Resultados}

Não foi observada diferença no peso final (Kruskal Wallis statistic $=6,01 ; \mathrm{P}=0,10$ ), no consumo de ração $(\mathrm{F}=1,48 ; \mathrm{P}=0,24)$ e ingestão de líquido $(\mathrm{F}=0,02 ; \mathrm{P}=0,99)$ (TABELA 2). $\mathrm{O}$ consumo médio de cafeína nos grupos COCAF e TCAF foi $6,1 \pm 0,8 \mathrm{mg} \cdot \mathrm{kg}^{-1} \cdot \mathrm{dia}^{-1}$.
Não foram observadas diferenças significativas na concentração sérica de cálcio entre os grupos ( $\mathrm{F}$ $=0,48, \mathrm{P}>0,05)$. Os níveis de lactato sanguíneo foram significativamente menores nos animais treinados $(\mathrm{F}=8,10 ; \mathrm{P}=0,002)$, em relação aos animais dos grupos sedentários (TABELA 2).

TABELA 2 - Média edesvio padrão da variação do peso, consumo líquido ederação eníveis séricos delactato ecálcio.

\begin{tabular}{lcccc}
\hline & SCO & SCAF & TCO & TCAF \\
\hline Peso corporal $(\mathrm{g})$ & $363,1 \pm 24,6$ & $339,5 \pm 26,8$ & $332,0 \pm 25,5$ & $326,2 \pm 24,5$ \\
Consumo de ração (g/100 g de peso) & $6,1 \pm 0,6$ & $6,1 \pm 1,2$ & $6,1 \pm 0,7$ & $6,1 \pm 0,7$ \\
Ingestão líquida (ml/100 g de peso) & $11,8 \pm 2,2$ & $12,1 \pm 3,3$ & $12,1 \pm 3,1$ & $15,5 \pm 6,5$ \\
Lactato $(\mathrm{mg} / \mathrm{dl})$ & $36,2 \pm 14,1$ & $36,8 \pm 11,5$ & $12,5 \pm 3,4^{*}$ & $18,5 \pm 4,8 \#$ \\
Cálcio sérico $(\mathrm{mg} / \mathrm{dl})$ & $8,5 \pm 1,7$ & $9,5 \pm 1,7$ & $9,1 \pm 2,2$ & $8,7 \pm 1,5$ \\
\hline
\end{tabular}

* $\mathrm{P}<0,05$, SCO $x$ TCO teste ANOVA two-way e "post hoc" teste de Tukey;

\# $\mathrm{P}<0,05$, SCAF e TCAF, teste ANOVA two-way e "post hoc" de Tukey. 
Não foi observada diferença nos valores de carga máxima (Kruskal Wallis statistic $=2,30 ; \mathrm{P}=$ $0,51)$, limite de elasticidade $(\mathrm{F}=0,13 ; \mathrm{P}=0,93) \mathrm{e}$ coeficiente de rigidez $(\mathrm{F}=0,43 ; \mathrm{P}=0,71)$ entre os grupos (FIGURA 1).

A análise histológica do fêmur não demonstrou alteração significativa na espessura do disco epifisário distal entre os grupos estudados (Kruskal Wallis statistic $=1,39 ; \mathrm{P}=0,70)$ (FIGURA 2a). Todos os animais apresentaram disco epifisário distal. Animais submetidos à dieta com cafeína e sedentários (SCAF) apresentaram maior espessura do disco epifisário proximal (Kruskal Wallis statistic
$=11,74 ; \mathrm{P}=0,008)$, em relação ao grupo $\mathrm{SCO}$ $(\mathrm{P}<0,05$, teste de Dunn) (FIGURA 2b). Não foi observada diferença entre a espessura do disco epifisário proximal nos grupos $\mathrm{SCO}$ e $\mathrm{TCO}(\mathrm{P}>$ 0,05, teste de Dunn), TCO e TCAF ( $\mathrm{P}>0,05$, teste de Dunn). Oito animais (22\%) apresentaram ossificação completa do disco epifisário proximal, sendo três no grupo SCO, um no SCAF, dois no TCO e dois no TCAF.

Quanto à formação de osso primário, não foram observadas diferenças significativas $(\mathrm{F}=1,88 ; \mathrm{P}=$ $0,15)$ nas áreas ocupadas pelas trabéculas ósseas do osso esponjoso entre os grupos estudados (FIGURA 3).
A = Carga máxima;

$B=$ Coeficiente de rigidez;

$\mathrm{C}=$ Limite de elasticidade; Dados expressos em média e desvio padrão; Teste Kruskal-Wallis ( $P$ $>0,05)$.
Disco epifisário da epífise proximal (A) e distal (B);

Não foi observada diferença significativa entre os grupos, no disco epifisário proximal; Animais do grupo SCAF apresentaram discoepifisário proximal mais espesso; Dados expressos em média e desvio padrão; * $P<0,05$, em relação ao grupo $\mathrm{CO}$, teste ANOVA two way e "post hoc" de Tukey.
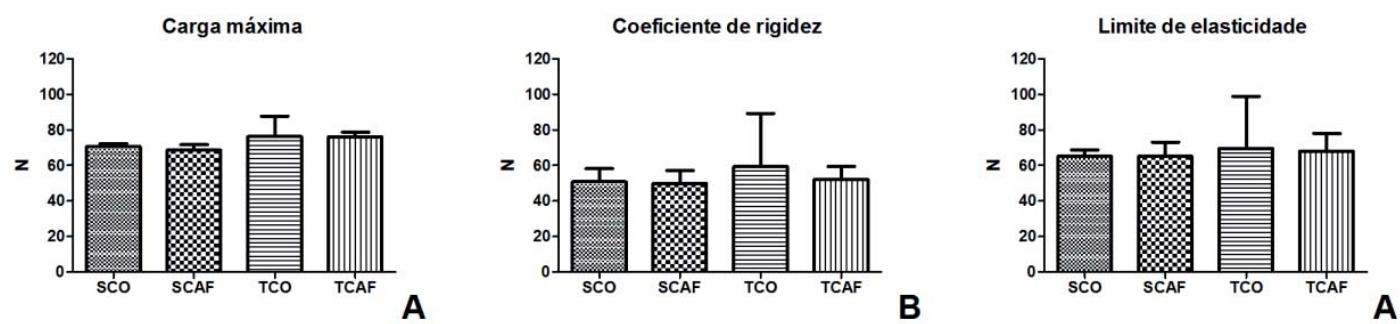

FIGURA 1 - Ensaios biomecânicos expressos em Neutons (N) em tíbia deanimais sedentários (SCO), sedentários submetidos àingestão crônica de cafeína (SCAF), treinados (TCO) etreinados esubmetidos aingestão crônica de cafeína (TCAF).
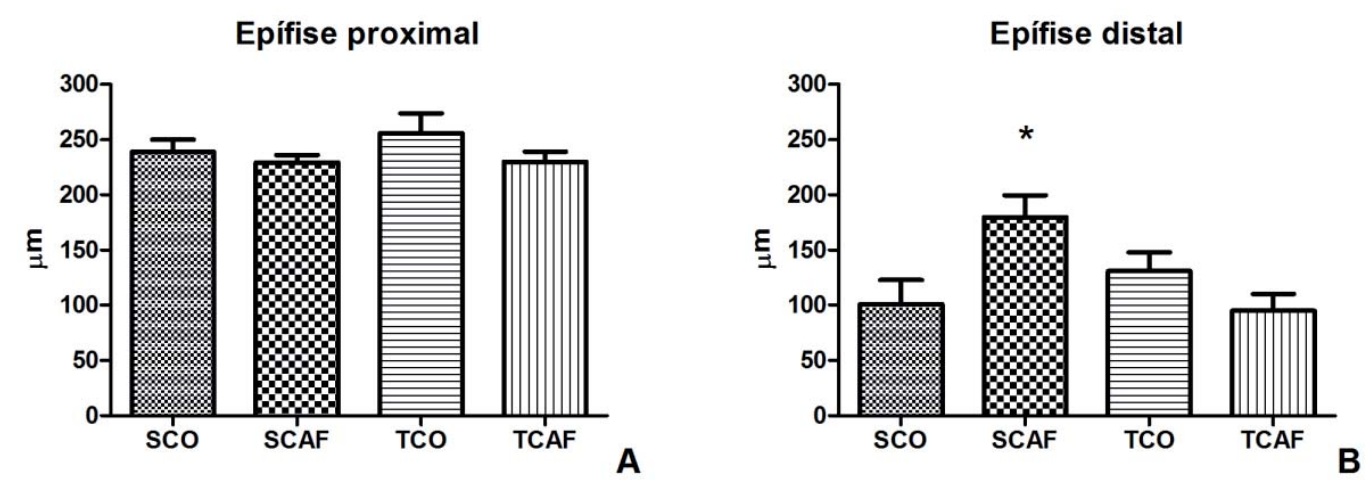

FIGURA 2 - Espessura do disco epifisário distal e proximal do fêmur de animais sedentários (SCO), sedentários submetidos àingestão crônica de cafeína (SCAF), treinados (TCO) etreinados esubmetidos aingestão crônica de cafeína (TCAF).

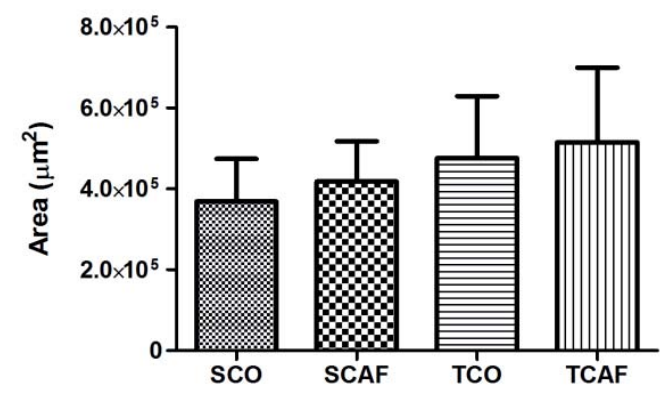

FIGURA 3 - Área deosso esponjoso do fêmur deanimais sedentários (SCO), sedentários submetidosàingestão crônica de cafeína (SCAF), treinados (TCO) e treinados e submetidos a ingestão crônica de cafeína (TCAF). 


\section{Discussão}

Os resultados do presente estudo sugerem que as propriedades biomecânicas e morfológicas no tecido ósseo em crescimento não foram alteradas com a associação da administração crônica da cafeína e do protocolo de natação. Estudos em animais aplicando exercícios de natação sugerem que ocorre um aumento da atividade osteoblástica e das propriedades biomecânicas do tecido ósseo, mesmo na ausência de alteraçōes histomorfométricas (HART, SHAW, VAJDA, Hegsted \& Miller, 2001; Huang et al., 2003, 2010; Warner, Shea, Miller \& Shaw, 2006). Em protocolo de exercício de natação semelhante ao aplicado no presente estudo, foi observado aumento na carga máxima e módulo de Young no exercício com $2 \%$ de carga, enquanto a intensidade de $4 \%$ diminuiu as propriedades biomecânicas do tecido ósseo femoral (HuANG et al., 2003, 2010). A carga progressiva e o tempo treinamento aplicados no presente estudo não provocaram alterações significativas nas propriedades biomecânicas. Porém, também não foram observadas alteraçõos biomecânicas significativas quando a cafeína foi administrada concomitantemente ao treinamento utilizado.

O curto intervalo de treinamento e a modalidade de exercício aplicado aos animais em estudos foi capaz de promover adaptação aeróbica ao exercício, reduzindo os níveis séricos de lactato. No entanto, o protocolo de exercício não promoveu adaptações morfológicas e biomecânicas sobre o tecido ósseo. Estudos anteriores reportando o aumento do volume das trabéculas ósseas e das propriedades biomecânicas ósseas aplicaram protocolos de treinamento em esteira de 10 a 19 semanas, o que pode ter estimulado de forma mais eficiente a ossificação primária (HUANG et al., 2002, 2003, 2010; Tromp, Bravenboer, Tanck, OOSTLANDER, Holzmann, Kostense, RoOs, Burger, HUISKES \& LiPS, 2006).

O consumo crônico de cafeína tem sido associado ao maior risco de desenvolvimento de lesões osteoporóticas, pois a droga diminui a densidade mineral óssea e interfere no metabolismo do cálcio, ostoblastos e osteoclastos (Body, Bergmann, BoOnen, Boutsen,Bruyere,DeVogelaer, Goemaere, Hollevoet, Kaufman, Milsen, Rozenderg \& Reginster, 2011; Duarte et al., 2009; Liu et al., 2011; Lu, LAI \& CHAN, 2008; RAPURI et al., 2001; Tsuang, Sun, Chen, Sun \& Chen, 2006). Embora exercícios de impacto possam favorecer o desenvolvimento de uma estrutura óssea mais resistente a testes bimecânicos, a natação parece não aumentar de forma significativa o volume e a resistência do tecido ósseo, e pode provocar redução da densidade mineral óssea em atletas jovem (CARBUHN, Fernandez, BragG, Green \& Crouse, 2010; Hind et al., 2011; MudD, ForNetTI \& PIVARNIK, 2007). O consumo crônico de cafeína pode inibir o processo de remodelamento do tecido ósseo, diminuindo o pico de massa óssea em indivíduos jovens. No entanto, poucos estudos avaliaram o consumo crônico de cafeína sobre a mineralização do tecido ósseo em indivíduos jovens (HUANG et al., 2002; LiBUDA et al., 2008; WeTMORE et al., 2008). Estudos em animais demonstram que o consumo crônico de cafeína tem atividade pró-resorptiva, diminui a densidade mineral óssea e compromete a ossificação dos discos epifisários e o processo de reparo ósseo (DUARTE et al., 2009; LiU et al., 2011). Por outro lado, estudos em humanos sugerem que o consumo de bebidas cafeínadas não altera de forma significativa a densidade mineral óssea em mulheres jovens (WETMORE et al., 2008).

No presente estudo, embora o crescimento dos discos epifisários dos animais do grupo controle e treinados com e sem cafeína apresentassem padrão normal (Reno, Mcburney, Lovejoy \& Horton We, 2006; Roach, Mehta, Oreffo, Clarke \& Cooper, 2003), os ratos do grupo SCAF apresentaram maior espessura do disco epifisário proximal comparado ao controle e $22 \%$ dos animais SCAF apresentaram calcificação do disco epifisário proximal, sugerindo que ocorreu um comprometimento do crescimento ósseo dos animais sedentários e tratados com cafeína. O consumo de altas doses de cafeína (10 $\mathrm{mg} / 100 \mathrm{~g}$ de peso corporal por dia) associado a protocolos de exercícios demonstraram resultados semelhantes em relação ao comportamento do disco epifisário proximal (HuANG et al., 2002), com o aumento na espessura da placa de crescimento da tíbia proximal e maior número de células na zona proliferativa. Por outro lado, há evidências de que baixas doses de cafeína não provocam alterações na histomorfometria óssea e marcadores séricos do metabolismo mineral ósseo, embora a cafeína tenha aumentado a secreção de osteocalcina, um fator de crescimento regulador da formação de calcificação da matriz óssea (GlajCHEN, Ismail, Epstein, Jowell \& Fallow, 1988). No entanto, Liu et al. (2011) demonstram que animais jovens suplementados com cafeína apresentam aumento da ativação de osteoclastos, aumento da expressão do ligante do receptor ativador do fator nuclear 
kappa B (RANKL) e inibição da expressão de osteoprotegerina, além da redução da densidade mineral óssea. Os resultados divergentes em relação a estudos anteriores podem ter ocorrido devido ao maior tempo de exposição à cafeína realizada nos referidos estudos e as dosagens utilizadas.

Além do tempo de exposição à cafeína, a concentração de cafeína também é relevante em algumas pesquisas. Por exempo, em pesquisas com animais, LACERDA et al. (2010) administraram $50 \mathrm{mg} / \mathrm{ml}$ de cafeína por 42 dias e DuARTE et al. (2009) utilizaram doses de cafeína equivalentes a $10 \mathrm{mg} / 100 \mathrm{~g}$ de peso corporal durante 56 dias. Ambos os estudos concluíram que existe uma ação negativa da cafeína sobre o metabolismo ósseo. No nosso estudo, foi utilizado $1 \mathrm{mg} / \mathrm{ml}$ de cafeína, equivalente a aproximadamente $6 \mathrm{mg} / \mathrm{kg}$, doses consideravelmente menores que as utilizadas por LACERDA et al. (2010) e DuARTE et al. (2009). Em conjunto, o resultado destes e de outros estudos sugerem que a cafeína administrada cronicamente tem o potencial de interferir com o crescimento dos ossos longos, dependendo da dose e do tempo de utilização. A ingestão crônica de cafeína associada ou não ao protocolo de exercício utilizado nesta pesquisa não foi capaz de alterar as propriedades biomecânicas no sistema ósseo de ratos Wistar.
O exercício aplicado no presente estudo simulou um treinamento aeróbio de baixa intensidade, provavelmente induzindo um aumento do metabolismo aeróbio e reduzindo a concentração sérica de lactato (Carvalho, Masuda \& Pompeu, 2005; Ravi Kiran, Subramanyam \& Asha Devi, 2004). Porém, o exercício não promoveu alterações morfológicas do tecido ósseo primário ou alteração das propriedades biomecânicas.

Concluímos que a administração crônica de cafeína associada ao exercício de natação não provocou alteração das propriedades biomecânicas e morfologia do tecido ósseo. A administração crônica de cafeína em animais sedentários sugere que ocorra um atraso no processo de ossificação do disco epifisário. No entanto, a extrapolação de resultados em relação a administração de doses seguras e eficientes de cafeína ou bebidas e suplementos cafeinados em praticantes de natação jovens deve aguardar resultados que demonstrem os efeitos da cafeína sobre o modelo moléculas reguladoras do metabolismo ósseo. Estudos experimentais, utilizando protocolos de exercício em intensidade e modalidades diferentes, tais como exercícios de força e esteira, são necessários para esclarecer o impacto da administração crônica de cafeína.

\begin{abstract}
Effect of exercise training and chronic caffeine intake on bone tissue of young rats

Effects of swimming training and chronic caffeine intake on bone tissue of young rats were investigated. Young Wistar rats were allocated into 4 groups: sedentary control (SCO), sedentary + caffeine (SCAF), trained (TCO) and trained + caffeine (TCAF); they received $1 \mathrm{mg} / \mathrm{ml}$ of caffeine diluted in water for 30 days (SCAF and TCAF) and were submitted to swimming training of moderate intensity for 21 days (TCO and TCAF). The left tibia was subjected to the biomechanical test for determination of the coefficient of stiffness, yield and maximum load. The immature bone tissue area and thickness of growth plates were evaluated in the femur. No changes were observed in biomechanical properties and the area occupied by immature bone tissue. However, SCAF group presented greater thickness in distal growth plate. The results suggest that the moderate intensity swimming training and caffeine consumption were not able to promote changes in morphology and biomechanical properties of bone tissue.
\end{abstract}

UnIterms: Bone; Caffeine; Exercise. 


\section{Resumen}

Efecto del entrenamiento físico y la ingestión crónica de cafeína sobre El hueso de ratas jóvenes

Se evaluaram los efectos del consumo crónico de cafeína y la natación em el hueso. Ratas Wistar jóvenes $(n=32)$ divididas en cuatro grupos: sedentarios control (SCO), sedentarios + cafeína (SCAF), entrenados (TCO) y entrenados + cafeína (TCAF), recibieron $1 \mathrm{mg} / \mathrm{ml}$ de cafeína en agua durante 30 dias (SCAF e TCAF) e fueron sometidos 21 días de la natación moderada. La tibia izquierda se sometió a una prueba biomecánica para determinar la coeficiente de la rigidez, el limite de elasticidad y el punto de carga máxima. El area de hueso imaturo e de la zona de la placa de crescimiento proximal e distal se analizó em el fêmur. No se observaron cambios en las propiedades biomecánicas y el déposition de hueso inmaturo. Animales SCAF tenía más grueso de la placa de crescimiento distal. Los resultados sugieren que entrenamento moderalado de la natación y el cosumo crônico de cafeína no cambió la morfología y las propiedades biomecánicas del hueso.

Palabras clave: Hueso; Cafeína; Ejercicio.

\section{Referências}

BODY, J.J.; BERGMANN, P.; BOONEN, S.; BOUTSEN, Y.; BRUYERE, O.; DEVOGELAER, J.P.; GOEMAERE, S.; HOLLEVOET, N.; KAUFMAN, J.M.; MILSEN, K.; ROZENDERG, S.; REGINSTER, J.Y. Non-pharmacological management of osteoporosis: a consensus of the Belgian Bone Club. Osteoporosis International,London, v.22, n.11, p. 2769-88, 2011. BURKE, L.M. Caffeine and sports performance. Applied Physiology, Nutrition and Metabolism, Ottawa, v.33, n.6, p.1319-34, 2008.

CARBUHN, A.F.; FERNANDEZ, T.E.; BRAGG, A.F.; GREEN, J.S.; CROUSE, S.F. Sport and training influence bone and body composition in women collegiate athletes. Journal of Strength and Conditioning Research, Champaign, v.24, n.7, p.1710-7, 2010.

CARVALHO, J.F.; MASUDA, M.O.; POMPEU, F.A. Method for diagnosis and control of aerobic training in rats based on lactate threshold. Comparative Biochemistry and Physiology - Part A: Molecular \& Integrative Physiology, New York, v.140, n.4, p.409-13, 2005.

DASCOMBE, B.J.; KARUNARATNA, M.; CARTOON, J.; FERGIE, B.; GOODMAN, C. Nutritional supplementation habits and perceptions of elite athletes within a state-based sporting institute. Journal of Science and Medicine in Sport, Belconnen, v.13, n.2, p.274-80, 2010.

DUARTE, P.M.; MARQUES, M.R.; BEZERRA, J.P.; BASTOS, M.F. The effects of caffeine administration on the early stage of bone healing and bone density: a histometric study in rats. Archives of Oral Biology, Oxford, v.54, n.8, p.717-22, 2009. GLAJCHEN, N.; ISMAIL, F.; EPSTEIN, S.; JOWELL, P.S.; FALLOW, M. The effect of chronic caffeine administration on serum markers of bone mineral metabolism and bone histomorphometry in the rat. Calcified Tissue International, Berlin, v.43, n.5, p.277-80, 1988.

GOLDSTEIN, E. R.; ZIEGENFUSS, T.; KALMAN, D.; KREIDER, R.; CAMPBELL, B.; WILBORN, C; TAYLOR, L.; WILLOUGHBY, D.; STOUT, J.; GRAVES, B.S.; WILDMAN, R.; IVY, J.L.; SPANO, M.; SMITH, A.E.; ANTONIO, J. International society of sports nutrition position stand: caffeine and performance. Journal of the International Society of Sports Nutrition, Woodland Park, v.7, n.1, p.5, 2010.

GOULET, G.C.; HALONEN, N.R.; KOCH, L.G.; BRITTON, S.L.; ZERNICKE, R.F.; KOZLOFF, K.M. Osteoblast response to ovariectomy is enhanced in intrinsically high aerobic-capacity rats. Calcified Tissue International, Berlin, v.88, n.4, p.325-35, 2011. HALLSTROM, H.; WOLK, A.; GLYNN, A.; MICHALSSON, K. Coffee, tea and caffeine consumption in relation to osteoporotic fracture risk in a cohort of Swedish women. Osteoporosis International, London, v.17, n.7, p.1055-64, 2006. HANSEN, S.A.; FOLSOM, A.R.; KUSHI, L.H.; SELLERS, T.A. Association of fractures with caffeine and alcohol in postmenopausal women: the Iowa Women's Health Study. Public Health Nutrition, Wallingford, v.3, n.3, p.253-61, 2000. HART, K.J.; SHAW, J.M.; VAJDA, E.; HEGSTED, M.; MILLER, S.C. Swim-trained rats have greater bone mass, density, strength, and dynamics. Journal of Applied Physiology, Bethesda, v.91, n.4, p.1663-8, 2001. 
HIND, K.; GANNON, L.; WHATLEY, E.; COOKE, C.; TRUSCOTT, J. Bone cross-sectional geometry in male runners, gymnasts, swimmers and non-athletic controls: a hip-structural analysis study. European Journal of Applied Physiology, Berlin, v.112, n.2, p.535-4, 2012.

HUANG, T.H.; HSIEH, S.S.; LIU, S.H.; CHANG, F.L.; LIN, S.C.; YANG, R.S. Swimming training increases the postyield energy of bone in young male rats. Calcified Tissue International, Berlin, v.86, n.2, p.142-53, 2010.

HUANG, T.H.; LIN, S.C.; CHANG, F.L.; HSIEH, S.S.; LIU, S.H.; YANG, R.S. Effects of different exercise modes on mineralization, structure, and biomechanical properties of growing bone. Journal of Applied Physiology, Bethesda, v.95, n.1, p.300-7, 2003.

HUANG, T.H.; YANG, R.S.; HSIEH, S.S.; LIU, S.H. Effects of caffeine and exercise on the development of bone: a densitometric and histomorphometric study in young Wistar rats. Bone, Elmsford, v.30, n.1, p.293-9, 2002.

KEMMLER, W.; VON STENGEL, S.; BEBENEK, M.; ENGELKE, K.; HENTSCHKE, C.; KALENDER, W.A. Exercise and fractures in postmenopausal women: 12-year results of the Erlangen Fitness and Osteoporosis Prevention Study (EFOPS). Osteoporosis International, London, v.23, n.4 p.1267-76, 2012.

LACERDA, S.A.; MATUOKA, R.I.; MACEDO, R.M.; PETENUSCI, S.O.; CAMPOS, A.A.; BRENTEGANI, L.G. Bone quality associated with daily intake of coffee: a biochemical, radiographic and histometric study. Brazilian Dental Journal, Ribeirão Preto, v.21, n.3, p.199-204, 2010.

LIBUDA, L.; ALEXY, U.; REMER, T.; STEHLE, P.; SCHOENAU, E.; KERSTING, M. Association between long-term consumption of soft drinks and variables of bone modeling and remodeling in a sample of healthy German children and adolescents. American Journal of Clinical Nutrition, Bethesda, v.88, n.6, p.1670-7, 2008.

LIU, S.H.; CHEN, C.; YANG, R.S.; YEN, Y.P.; YANG, Y.T.; TSAI, C. Caffeine enhances osteoclast differentiation from bone marrow hematopoietic cells and reduces bone mineral density in growing rats. Journal of Orthopaedic Research, New York, v.9, n.6, p.954-60, 2011.

LORENZO, A.M.; LEÓN, D.; CASTILLO, C.A.; RUIZ, M.A.; ALBASANZ, J.L.; MARTÍN, M. Maternal caffeine intake during gestation and lactation down-regulates adenosine A1 receptor in rat brain from mothers and neonates. Journal of Neuroscience Research, New York, v.88, n.6, p.1252-61, 2010.

LU, P.Z.; LAI, C.Y.; CHAN, W.H. Caffeine induces cell death via activation of apoptotic signal and inactivation of survival signal in human osteoblasts. International Journal of Molecular Sciences, Basel, v.9, n.5, p.698-718, 2008.

MANN, V.; HUBER, C.; KOGIANNI, G.; JONES, D.; NOBLE, B. The influence of mechanical stimulation on osteocyte apoptosis and bone viability in human trabecular bone. Journal of Musculoskeletal and Neuronal Interactions, Kifissia, v.6, n.4, p.408-17, 2006.

MUDD, L.M.; FORNETTI, W.; PIVARNIK, J.M. Bone mineral density in collegiate female athletes: comparisons among sports. Journal of Athletic Training, Dallas, v.42, n.3, p.403-8, 2007.

RAPURI, P.B.; GALLAGHER, J.C.; KINYAMU, H.K.; RYSCHON, K.L. Caffeine intake increases the rate of bone loss in elderly women and interacts with vitamin D receptor genotypes. American Journal of Clinical Nutrition, Bethesda, v.74, n.5, p.94-700, 2001.

RAVI KIRAN, T.; SUBRAMANYAM, M.V.; ASHA DEVI, S. Swim exercise training and adaptations in the antioxidant defense system of myocardium of old rats: relationship to swim intensity and duration. Comparative Biochemistry and Physiology Part B: Biochemistry and Molecular Biology, Oxford, v.137, n.2, p.187-96, 2004.

RENO, P.L.; MCBURNEY, D.L.; LOVEJOY, C.O.; HORTON WE, J.R. Ossification of the mouse metatarsal: differentiation and proliferation in the presence/absence of a defined growth plate. Anatomical Record Part A: Discoveries in Molecular, Cellular and Evolutionary Biology, Hoboken, v.288, n.1, p.104-18, 2006.

ROACH, H.I.; MEHTA, G.; OREFFO, R.O.; CLARKE, N.M.; COOPER, C. Temporal analysis of rat growth plates: cessation of growth with age despite presence of a physis. Journal of Histochemistry and Cytochemistry, Baltimore, v.51, n.3, p.373-83, 2003.

TROMP, A.M.; BRAVENBOER, N.; TANCK, E.; OOSTLANDER, A.; HOLZMANN, P.J.; KOSTENSE, P.J.; ROOS, J.C.; BURGER, E.H.; HUISKES, R.; LIPS, P. Additional weight bearing during exercise and estrogen in the rat: the effect on bone mass, turnover, and structure. Calcified Tissue International, Berlin, v.79, n.6, p.404-15, 2006.

TSUANG, Y.H.; SUN, J.S.; CHEN, L.T.; SUN, S.C.; CHEN, S.C. Direct effects of caffeine on osteoblastic cells metabolism: the possible causal effect of caffeine on the formation of osteoporosis. Journal of Orthopaedic Surgery and Research, London, v.1, p.7, 2006.

WARNER, S.E.; SHEA, J.E.; MILLER, S.C.; SHAW, J.M. Adaptations in cortical and trabecular bone in response to mechanical loading with and without weight bearing. Calcified Tissue International, Berlin, v.79, n.6, p.395-403, 2006. 
WETMORE, C.M.; ICHIKAWA, L.; LACROIX, A.Z.; OTT, S.M.; SCHOLES, D. Association between caffeine intake and bone mass among young women: potential effect modification by depot medroxyprogesterone acetate use. Osteoporosis International, London, v.19, n.4, p.519-27, 2008.

Solange de Paula Ramos

Rod. Celso Garcia Cid - PR 445 km 380 86051-990 - Londrina - PR - BRASIL e-mail: ramossolange@yahoo.com
Recebido para publicação: 14/ 09/2011

Revisado: 14/03/2012

Aceito: 02/ 04/ 2012 